\title{
Correspondence
}

Letters to the Editor should not exceed 500 words.

Computars on tije March

M. P. McBrien, F.R.C.S. ; R. de Soldenhoff, B.SC.

Mobile Coronary Care Teams

A. A. Jennifer Adgey, M.R.C.P., and S. A. A. A. Jennifer Ad

Car Driving and the Heart

Driving and the Heart

G. Wiseman, M.D. ; H. Franks, D.P.H. ..4428

Treating Preinfected Wounds

J. A. Raeburn, M.B. ; P. J. Whitfield, B.A. ;

enal Transplantation and Leucocyte

Migration

Migration
W. J. Dempster, F.R.C.s. ................428

Vaccination against Whooping-cough

F. T. Perkins, PH.D.

Acetate and Bacteria

Saving the Grossly Disabled

.............430

R. C. Sanders, M.R.C.P. ..................4 430

Purpura and Ibuprofen

T. Ward, D.C.H.
Career Prospects for Medically Qualified Dentists

F. G. Hardman, M.B., F.D.s. R.C.S. .......430

Agricultural Accidents

R. M. Archibald, D.I.H.

Fibrinolytic Enzyme System

J. Bonnar, M.R.C.o.G., and others ...... 430

Analgesic Nephropathy

D. Bell, M.B., and others

Malignant Granuloma

Malignant Granuloma

I. Friedmann, F.C.PATH., and D. A. Osborn,
F.C.PATH.

Battered Babies

B. Barnett, D.P.M

Metabolism in Parkinsonian Patients

J. Braham, M.D., and A. Szeinberg, PH.D. 432

Survival after 195 Defibrillations

M. M. Kubik, M.D., and P. K. Das Gupta,

M.R.C.P.ED. . . o. Öbstetric Analgesia
Methoxyflurane for

M. Rosen, F.F.A. R.C.S., and others .......432

Clinical Data and Statistical Interpretation

J. S. Price, D.P.M. .......................433
Inappropriate Lactation

R. P. Shearman, F.R.C.o.G. ............443

Congenital Anomalies of the Vas Deferens

G. T. Watt, F.R.C.s. .................... 433

Unwanted Blessings

P. H. Addison, M.R.C.S. ...................433

Solitary Confinement

R. I. K. Blyth, M.R.

The Consultant's Job

D. St. C. L. Henderson, F.R.C.S.ED., and

others; M. Hamilton, F.R.C.P., and others 434

Regional Hospital Medical Staff

G. G. Muir, M.D. ......................435

Specialist Registration and tye Armed Forces

Surgeon Commander G. A. R. Giri,

D.P.H

Postgraduate Courses and Seniority

H. G. Gibson, M.B.

Fees for Expert Witnesses

G. F. Petty, M.R.C.S. ...

Christmas Gifts Fund Appeal

Sir Thomas Holm:s Sellors, P.R.C.s. .....435

\section{Computers on the March}

SIR,-Y Your leading article " Computers on the March" (18 October, p. 124) highlights only a few of the problems of introducing computers into medicine. Dr. J. H. Mitchell (18 October, p. 157) underlines two basic difficulties, which I believe will prevent the computer from intruding further into the clinical field.

Firstly, the history obtained from most patients in a busy outpatient department or ward is likely to be put together in a somewhat disjointed fashion; this depends on the mutual concentration, interest, and experience of the doctor on the one hand and the ability to communicate, the actual illness, and the state of mental anxiety of the patient on the other. The resulting data are bound to be "vague and unreliable," to quote Dr. Mitchell, and can never be suitable for computer input. Conversion of these human facts into "standard" questions and "standard" answers requires a vast increase in secretarial and programming personnel, a great deal of added "time per patient," and is plainly unworkable in the National Health Service.

Secondly, the record of examination of a patient can only contain certain parameters of objective assessment-for example, temperature, pulse, blood pressure-and these can be notoriously unreliable at a first interview. Other findings at a preliminary, and often cursory, examination are purely subjective, and depend considerably on the skill, experience, and individual variation among doctors. Such data are likewise unsuitable for programming a computer.

In certain areas of hospital work computers are invaluable, but in the strictly clinical field I feel that the only time that the medical profession will consent to using a common terminology of computer language will be when "standard" doctors are turned out at the end of "standard" courses from "standard" medical schools, and when their patients stop being human.-I am, etc.,

$$
\begin{aligned}
& \text { St. Thomas's Hospital, } \\
& \text { London S.E.1. }
\end{aligned}
$$

M. P. MCBRIEN.

SIR,-After a rather tardy start the medical profession in Great Britain is seriously contemplating the use of computers in this the most conservative of professions. $\Lambda$ s Dr. M. Marinker points out ${ }^{1}$ there are several studies going on in general practice attempting to computerize records. A number of Scottish and English hospitals have tried to computerize small areas of their records. ${ }^{2}$

Dr. D. E. Clark ${ }^{3}$ tells us that $75 \%$ of the activity of a hospital is concerned with the processing of information. Jydstrup and Gross ${ }^{4}$ inform readers that the present cost of a hospital's information system or processing techniques is much higher than we appreciate, and may be as much as $25 \%$ of the total hospital operating budget.

It is indeed disappointing to see the article by Dr. J. H. Mitchell (18 October, p. 157), a distinguished expert on the processing of medical records, in which he condemns exciting research and investigation into this field as "fantastically elaborate and expensive." When the process of recording and retrieval of information is of such importance, then expensive schemes are valid. The storage of many patient/years of information is a simple and economical computer process, and destruction of records may well meet with condemnation from our successors in their studies or topics of interest and research into our diseases of the 60's and 70's. Our danger is not the diversion of attention from more valuable uses to which computers might be put, but reluctance to spend time and effort on the resources at hand and to learn how to use them to their full efficiency. -I am, etc.,

\section{Richard DE SOLdenhofF.}

Edinburgh Librarian.

REFERENCES

1 Marinker, M., Practitioner, 1969, 203, 285. Kay, F. F. Roy, A. D., Cleary, J. J., and Clark, D. E., Practitioner, 1969, 203,313 Jydstrup, R. A A and Gross, M. J., Health Ser-
vices Research, 1966, 1, 235.

\section{Mobile Coronary Care Teams}

SIR,-We believe that it would be singularly unfortunate if the concept of prehospital coronary care were to be judged by the results reported by Dr. H. A. Dewar and his colleagues (25 October, p. 226). The poor results obtained by the Newcastle unit, in contrast to the results obtained by the Belfast Mobile Coronary Care Unit, ${ }^{1-4}$ are due to fundamental differences in the operation of the units.

In Belfast the emphasis is on early initiation of coronary care; thus the median time between onset of symptoms and the initiation of coronary care by the mobile unit is two hours, and $26 \%$ of the patients managed by the Belfast unit are under intensive care within one hour. In contrast, the mean time quoted by Dr. Dewar and his colleagues is four and a half hours. Since the majority of deaths from myocardial infarction occur within two hours of the onset of symptoms, the Newcastle unit will have little effect on the mortality. It appears that the general practitioners of Newcastle upon Tyne have been ill informed as to the type of patient who is most likely to benefit from immediate 
coronary care. The patient with an apparently mild myocardial infarction is at as great a risk of developing fatal ventricular dysrhythmia as the patient with a clinically severe infarct. ${ }^{4}$

In Newcastle the interval between the receipt of the call from the practitioner and the arrival of the coronary care team with the patient (mean 21 minutes) contrasts with the Belfast time (median 10 minutes). The inordinate delay may contribute to the lack of interest of the Newcastle practitioners in the scheme. Dr. Dewar and his colleagues indicate that only $42 \%$ of the Newcastle practitioners use the mobile unit and that the number is not increasing. A questionary conducted by one of us (Dr. Zaidi) in March 1969 indicated that $89 \%$ of the Belfast practitioners use the mobile scheme.

Another important difference between the two schemes is that in Belfast only personnel who have gained experience in the hospital coronary care unit are allowed to go on the mobile team. We agree with Dr. Dewar and his colleagues that it is most important to have adequate inpatient coronary care facilities for reception of patients managed by a mobile unit. It should be stressed, however, that all the available data indicate that at least two-thirds of the deaths from myocardial infarction occur outside hospital and that therefore when problems of staffing exist priority should be given to staffing of the mobile unit.-We are, etc.

\section{A. A. Jennifer Adgey.}

S. A. ZAIDI

\section{Department of Cardiology,} Royal Victoria Hos
Belfast 12 6BA.

\section{REFERENCES}

1 Pantridge, J. F., and Geddes, J. S., Lancet, 1966, 1, 807. 2, 271. J. Fond, Adgey, A. A. J., Geddes, J. S., Mulholland,
H. C., Keegan, D. A. J., and Pantridge, J. F.,
Lancet, 1968, 2, 1097. 4 Adgey, A. A. J., Nelson, P. G., Scott, M. E. Geddes, J. S., Allen, D. J., Zaidi, S.

\section{Car Driving and the Heart}

SIR,-The effects of motor-car driving on the normal and abnormal heart, reported by Dr. P. Taggart and others (18 October, p. 130) are of considerable interest. I wonder, however, if these workers were to use as their control study the same subjects attempting to cross busy city roads, whether the final verdict would be reversed-that is, that a person in whom angina is easily provoked should be advised to be a driver rather than a pedestrian ?-I am, etc.,

\section{Physiology Department, he University}

SIR,-I trust the paper by Dr. P. Taggart and others (18 October, p. 130) does not induce readers to pursue their advice against the issue of driving licences to persons with angina and "borderline" failure. While the authors admit the existing evidence that syncopy from previously known coronary disease is rarely the cause of fatal traffic accidents, they seem quite prepared to deprive a very large number of people of their only means of getting about and continuing their employment on the basis of their very equivocal clinical findings in the cases they investigated.
We all know that these patients can continue to lead independent and useful lives for many years under favourable conditions. Hurrying about, carrying parcels, dodging traffic, and standing at bus stops are not less harassing to them than driving a light car with a good heater, and can lead to just as many accidents, involving others as well as themselves.

Car accidents are caused by errors of judgement more often due to latent illness, fatigue, haste, obstinacy, aggressiveness, or emotional instability than to patent heart disease. The heart patient knows he cannot afford to take chances, and will limit, by necessity if not by choice, the number, length, and speed of his car journeys and the size of his car. If his symptoms still cause distress or impairment of judgement when driving, he will pull into the side of the road, and if this happens too often he will be obliged to give up driving altogether for a time or permanently if need be. But this may not happen for five-or even 25 years after the first appearance of angina and symptoms of "borderline" failure.-I am etc.,

\section{Chigwell Urban District Council
Essex.}

\section{H. FRANKS}

\section{Treating Preinfected Wounds}

SIR,-Mr. J. W. S. Rickett and Mr. B. T. Jackson (25 October, p. 206) report a reduction in wound infection after appendicectomy in patients who received topical ampicillin during closure of the muscle layers of the wound. Before the significance of this finding can be assessed, one must surely know what organisms were cultured from the in fected wounds, and what methods of isolation were employed. The authors state that al wound infections grew "large bowel organisms." Were these Escherichia coli, Proteus sp., Pseudomonas pyocyanea, or what? Surely it is important to distinguish colonization of the wound with bacteria, an innocuous situation in most patients, from super infection, a dangerous precursor of systemic infection.

A final point about the study which disturbs me is the comparison of an antibiotic with a carbohydrate powder. In the laboratory in our department we have found that standard laboratory organisms grow rather well in solutions containing $1 \%$ lactose and some protein. Might not the powder have, in fact, encouraged additional infection? in fact, encou

\section{Royal Infirmary,}

JOHN A. RAEBURN.

SIR,-A query from a medically naive zoologist. Mr. J. W. S. Rickett and $\mathrm{Mr}$. B. T. Jackson (25 October, p. 206) conclude that their double-blind trial on the use of topical ampicillin in appendicectomy wounds " indicates that topical application of this drug reduces postoperative wound infection.'

The placebo used in their trial (lactose) is a nutrient substrate eminently utilizable by large-bowel organisms. Thus, might one not expect a significant increase in the incidence of wound infections in the placebo group compared with any experimental group, whether it were treated with ampicillin or sterile talcum powder?

Perhaps someone can convince me that treating preinfected wounds with bacterial substrates does not increase the incidence of overt infections.-I am, etc.,

\section{P. J. Whitfieid.}

Department of Zoology University of London King's College,
London W.C.2.

SIR,-I wonder whether Mr. J. W. S Rickett and Mr. B. T. Jackson (25 October, p. 206) realize that, by using lactose powder as a placebo in their double-blind trial of topical ampicillin in appendicectomy wounds, they may have invalidated their findings.

The vital requirement of the control placebo in a double-blind trial is that it mus be inactive in the specific context of the trial. While lactose is an excellent placebo in the controlled trial of almost any orally administered drug, in the specific context of the trial of a topical antibiotic it is far from inactive. The local high concentration of lactose which is produced by sprinkling it into the wound provides an excellent medium for the growth and multiplication of pathogenic bacteria. It is not, therefore, surprising that the control group in this trial had such a high infection rate.-I am, etc.,

School of Medicine,

Arnold G. Zermansky.

Leeds 2, Yorks.

\section{Renal Transplantation and Leucocyte Migration}

SIR,-The diagnosis of rejection of an allotransplanted kidney can be difficult, as pointed out by Dr. M. G. M. Smith and others (1 November, p. 275), but I feel that they have overplayed the limitations of conventional renal function tests.

If for a brief moment we set aside lymphocytes and antibodies and concentrate on the mechanics of rejection it will become apparent that some of us now agree that acute rejection equals an acute haemodynamic upset. ${ }^{1}$ This upset varies from frank exclusion of flow from the outer cortex to vascular mural oedema decreasing perfusion pressure, and the net result is impaired renal perfusion. The 15-minute phenol red test ${ }^{2}$ can detect this defect within 30 minutes of deciding to measure the effective renal plasma flow. If a functional pattern of impaired renal perfusion is detected by a low phenol red excretion, then a differential diagnosis from renal artery stenosis (by an arteriogram) and ureteric obstruction (by an I.V.P.) can be made long before the results of a leucocyte migrating test (20 hours) become available. Total renal blood flow is not reliableuntil rather late in rejection. What is important in the early stage is the distribution of the blood, and the effective renal plasma flow reflects this.-I am, etc.,

\section{W. J. Dempster.}

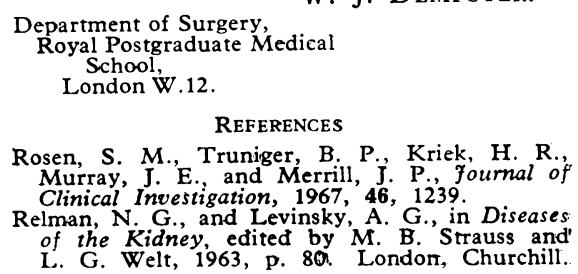

